\title{
Beautiful economic features of public landscaping in city beautiful
}

\author{
EMILSON CAPUTO DELFINO SILVA(2) E ADRIANA MARASCA ${ }^{(3)}$
}

\begin{abstract}
City beautiful was a movement of great reach and inspiration, which apparently, was initiated in Chicago in 1893 during the World's Columbian Exposition. The movement's premises were artistic, architectural, social, political and economic. Among the artistic and architectural aspects of the city beautiful movement, the provision of high quality public landscaping was of paramount importance. As for the economic rationale behind the movement, we encounter the thinking that a beautiful city should increase its residents' enjoyment of the city's attributes and hence attachment to the city, raise real estate values as well as expand city business, with larger sales of city goods and services to local and touristic customers. This paper examines the economic rationale behind the city beautiful movement. We consider a "regional" economy consisting of two adjacent cities, which are identical in many of its attributes, such as the sizes of their populations. We build a general equilibrium model for the agents (consumers and producers) in this economy and demonstrate that the economic rationale behind the city beautiful movement is sound. Each city's wealth and welfare are proportional to its quality level and a city's quality level is proportional to the city's public landscaping quality.
\end{abstract}

Keywords: economy, squares, parks, city's quality level

\section{INTRODUCTION}

City beautiful was a movement of great reach and inspiration, which apparently, was initiated in Chicago in 1893 during the World's Columbian Exposition. The movement's premises were artistic, architectural, social, political and economic. Among the artistic and architectural aspects of the city beautiful movement, the provision of high quality public landscaping was of paramount importance. As for the economic rationale behind the movement, we encounter the thinking that a beautiful city should increase its residents' enjoyment of the city's attributes and hence attachment to the city, raise real estate values as well as expand city business, with larger sales of city goods and services to local and touristic customers (CARLINO, 2009).

This paper examines the economic rationale behind the city beautiful movement. We consider a "regional" economy consisting of two adjacent cities, which are identical in many of its attributes, such as the sizes of their populations. We build a general equilibrium model for the agents (consumers and producers) in this economy and demonstrate that the economic rationale behind the city beautiful movement is sound. Each city's wealth and welfare are proportional to its quality level and a city's quality level is proportional to the city's public landscaping quality.

The city beautiful movement exemplifies the important economic role that public landscaping may play in city development. This fact, of course, is not surprising to landscaping researchers. As pointed out by PIVETTA et al. (2008), the traditional Greek "agoras" evolved over time and became important central squares in European cities - in these places, people gathered to enjoy the traits of city life, including the city center's public landscaping, theatrical showings, political speeches and the local market. These features of the European plaza or square are still very much alive today (FAYE and FUR, 2012).

\section{THE GENERAL EQUILIBRIUM MODEL}

Consider two neighboring cities in a particular region of the nation. For simplicity, we assume that the cities have fixed and identical population sizes and that there is no intercity or intra-city mobility. In order to capture the values that individuals place on the various attributes supplied at the city center, we assume that each city is circular. Since each city's population is fixed, we shall simply assume that each city has a radius equal to one unit of distance (which may be equivalent to one kilometer, ten kilometers, etc). We also assume that the unit circles do not intersect.

The unit circles are located next to each other on the Cartesian product. The center of city 1 is the point $(1,1)$ and the center of city 2 is the point $(4,1)$. The length of the distance between circles 1 and 2 is equal to one, being the distance between points $(2,1)$ and $(3,1)$.

Each city resident has two sources of wealth: (i) an equal share of profits produced by local industry; and (ii) an equal share of the proceeds from land sales in his/her community of residence. To keep things simple, we assume that the price of a property in each city is entirely given by the price of the land. Each individual's house is identical and has a fixed size.

Land prices vary according to the locations of the properties. All else the same, the land price reflects the desirability of visiting the center in order to enjoy the public landscaping (i.e., central square and public park) and consume privategoods and services that are supplied by centrally located firms (e.g., restaurants, cinemas, pharmacies, clothing stores, etc.) and public landscaping

\footnotetext{
(1) Recebido em 10 de maio de 2013 e aceito para publicação em 30 junho de 2013.

${ }^{(2)}$ Department of Marketing, Business Economics \& Law, University of Alberta Edmonton- Canadá

${ }^{(3)}$ Arquiteta, Edmonton- Canadá
} 
available in the center of the city in which the individual resides. In other words, for each individual, a visit to the city center is a complementary activity to enjoyment of public landscaping and consumption of centrally supplied private goods and services. Each individual faces a transportation cost for each visit made to the city center. This cost is proportional to the distance between the individual's residence and the city center. Hence, the most desirable locations to enjoy local public landscaping and consume local private goods and services in cities 1 and 2 are the points $(1,1)$ and $(4,1)$, respectively. As we see below, as one's residence is more distant from the city center, in any direction, the lower it is this individual's land price. The land price will fully capture the individual's transportation cost. In each city, the transportation cost faced by value all individuals who reside on a circumference of radius $r \in[0,1]$ is the same.

Each resident of any city also derives utility from visiting the center of the other city. During each "touristic" visit (i.e., a visit made to the other city), an individual enjoys the touristic city's public landscaping and consumes private goods and services supplied by centrally located firms. To keep things simple, we assume that the transportation cost of traveling from a city to another is the same for all tourists (e.g., all tourists travel by bus or another mode of public transport), where this cost is proportional to the distance between the two city centers (e.g., the public transport departs from each city center). The idea here is that to travel to the other city, individuals go to the center of their city first. Once there, they visit the city center and then travel to the other city (or vice versa, namely, travel to the other city first and then visit the center of their residential city later). This assumption seems reasonable if the number of touristic visits does not exceed the number of visits made to the city center for any individual; since, by combining the visits, each individual saves on transportation costs.

An individual's location in his/her city of residence determines this individual's type. The utility derived by an individual of type $r \in[0,1]$ in city $i, i=1,2$, is as follows:

$$
\begin{aligned}
U(r, i) \equiv & u\left(x_{i}(r), l_{i}(r), v_{i i}(r), v_{i j}(r), y_{i i}(r), y_{i j}(r), G_{i}, Q_{i}, Q_{j}\right) \\
& x_{i}(r)+f\left(l_{i}(r), v_{i i}(r), v_{i j}(r), y_{i i}(r), y_{i j}(r), G_{i}, Q_{i}, Q_{j}\right), i, j=1,2, j \neq i,
\end{aligned}
$$

where $x_{i}(r)$ is the individual's consumption of a composite consumption good (consisting of a basket of all private goods and services consumed by the individual other than the local and touristic private goods and services), $l_{i}(r)$ is the amount of land utilized, $v_{i i}(r)$ is the number of visits made to the center of the city in which the individual resides, $v_{i j}(r)$ is the number of touristic visits made to the center of city $j, y_{i i}(r)$ is the level of local private goods and services consumed, $y_{i j}(r)$ is the level of touristic private goods and services consumed, $G_{i}$ is the level of a composite local public good (consisting of a basket of all local public goods and services provided by the local government other than public landscaping such as primary education, police services, fire protection, public lightning, water, electricity, etc.), $Q_{i}$ is the level of public landscaping (or the quality level of its several attributes) provided in city $i$ and $Q_{j}$ is the level of public landscaping provided in city $j$.

We assume that $f($.$) \quad is increasing in all arguments,$ twice continuously differentiable, strictly concave and satisfies the following properties:
(i) $f_{l_{i} v_{i j}}=f_{l_{i} y_{i i}}=f_{l_{i} y_{i j}}=f_{l_{i} Q_{i}}=f_{l_{i} Q_{j}}=0$;
(ii) $f_{v_{i i} v_{i j}}=f_{v_{i i} y_{i j}}=f_{v_{i i} G_{i}}=f_{v_{i i} Q_{j}}=0$;
(iii) $f_{v_{i j} y_{i i}}=f_{v_{i j} G_{i}}=f_{v_{i j} Q_{i}}=0$;
(iv) $f_{y_{i i} y_{i j}}=f_{y_{i i} G_{i}}=f_{y_{i i} Q_{i}}=f_{y_{i i} Q_{j}}=0$;
(v) $f_{y_{i j} G_{i}}=f_{y_{i j} Q_{i}}=f_{y_{i j} Q_{j}}=0$;
(vi) $f_{G_{i} Q_{i}}=f_{G_{i} Q_{j}}=0$;

and (vii) $f_{Q_{i} Q_{j}}=0$. These restrictive properties allow us to consider the key relationships among the various goods consumed by the individuals. We wish to restrict the analysis as much as possible in order to derive fundamental insights regarding individual behavior.

Property (i) implies that the individual demand for land does not depend on the number of touristic visits, the levels of private goods and services consumed either locally or in the other city, the level of local of public landscaping, and the level of public landscaping provided in the other city. As for the other goods and services, it seems reasonable to suppose that an individual's demand for land in a particular city depends crucially on the level of composite local public good the city provides and on the number of visits the individual wishes to make to the city center; namely, $f_{l_{i} G_{i}}>0$ and $f_{l_{i} v_{i i}}>0$. The rationale for the relationship between demand for land and the level of composite of local public good is straightforward: an individual may select a particular basket of local public goods by "voting with his/her own feet." Hence, the benefit one derives from owning land in a particular city should be increasing in the level of that city's composite public good. As for the rationale between the demand for land and visits to the city center, it follows from the fact that, all else held constant, the larger the benefit an individual obtains from visiting the city center of a particular city the larger it will be this individual's desire to reside in this city (relative to residing in other cities). Hence, the demand for land in a particular city should increase with the number of visits an individual wishes to make to the city center of that city.

Property (ii) informs us that the individual demand for visits to one's city center does not depend on the number of touristic visits made, the level of consumption of touristic goods and services, the composite level of public good provided by the city in which one resides and the level of public landscaping provided by the other city. An individual's propensity to visit the city center should be higher the higher are the benefits from such a visit: these increase with the level of public landscaping and the level of consumption of local private goods and services. These facts imply that the demand for visits to the city center rises with both the level of public landscaping and the level of consumption of local private goods and services; namely, $f_{v_{i i} y_{i i}}>0$ and $f_{v_{i i} Q_{i}}>0$.

Property (iii) states that the individual demand for touristic visits does not depend on the level of consumption of local private goods and services, the level of composite 
local public good provided at one's city of residence, and the level of public landscaping provided at one's city of residence. Since the benefits associated with making a touristic visit increases with the level of public landscaping available at the touristic site and the level of consumption of touristic private goods and services. Hence, $f_{v_{i j} y_{i j}}>0$ and $f_{v_{i j} Q_{j}}>0$.

Property (iv) implies that the individual demand for local private goods and services does not depend on the level of consumption of touristic private goods and services, the level of composite local public good provided at one's city of residence, and the levels of public landscaping provided by both cities. Property (v) states that the individual demand for touristic services does not depend on the level of composite public good provided at one's city of residence, and the levels of public landscaping provided by both cities. Property (vi) informs us that the individual demand for the composite local public good provided at one's city of residence is independent of the levels of public landscaping provided by both cities. Finally, property (vii) says that the individual demand for public landscaping provided by one's city of residence does not depend on the level of public landscaping provided by the other city.

An individual of type $r$ in city $i$ faces the following budget constraint:

$p_{x} x_{i}(r)+p_{l i}(r)(1+\tau) l_{i}(r)+\delta\left(r v_{i i}(r)+3 v_{i j}(r)\right)+p_{y i}(r) y_{i i}(r)+p_{y j} y_{i j}(r)=w_{i},(1)$

where we assume that $p_{x}=1$; that is, all relative prices are measured in terms of the price of the composite price good. The left hand side of equation (1) gives us the total expenditure incurred by the consumer. This expenditure includes the land tax, $p_{l i}(r) \tau l_{i}(r)$, where $\tau \in(0,1)$ is the land tax rate, and the total transportation cost incurred by the individual, $\delta\left(r v_{i i}(r)+3 v_{i j}(r)\right)$. The distance covered between this individual's home and the city center is equal to $r$. To go to the center and return home, the individual covers a distance equal to $2 r$. Assuming that the cost per unit of distance is equal to $\kappa>0$, the total transportation cost of a visit is $2 \kappa r$. Letting $\delta=2 \kappa$, the transportation cost is $\delta r$. Since the individual makes $v_{i i}(r)$ visits to the center of the city in which he/she resides, the total cost of visiting the city center is thus $\delta r v_{11}(r)$. Similarly, the cost of traveling from one city center to the other and return is equal to $3 \delta$. Thus, the total cost of touristic visits is equal to $3 \delta v_{i j}(r)$.The term in the right hand side represents the individual's wealth. Since we assume that all individuals in city $i$ receive an equal share of profits produced by the local industry and an equal share of the proceeds of land sales in the city, all individuals have the same wealth.

An individual of type $r$ chooses consumption levels $\left\{x_{i}(r), l_{i}(r), v_{i i}(r), v_{i j}(r), y_{i i}(r), y_{i j}(r)\right\}$ to maximize $U(r, i)$ subject to the budget constraint (1).Consumers take prices, wealth, composite local public good levels and public landscaping levels as given. We assume that every individual consumes positive amounts of all goods and services in equilibrium. The first order conditions, which give us the solution to the constrained maximization problem, $\left\{x_{i}^{*}(r), l_{i}^{*}(r), v_{i i}^{*}(r), v_{i j}^{*}(r), y_{i i}^{*}(r), y_{i j}^{*}(r)\right\}, \quad$ are equations (1) and the following:

$$
\begin{aligned}
& f_{l_{i}}\left(l_{i}^{*}(r), v_{i i}^{*}(r), v_{i j}^{*}(r), y_{i i}^{*}(r), y_{i j}^{*}(r), G_{i}, Q_{i}, Q_{j}\right)=(1+\tau) p_{l i}(r), \\
& f_{v_{i i}}\left(l_{i}^{*}(r), v_{i i}^{*}(r), v_{i j}^{*}(r), y_{i i}^{*}(r), y_{i j}^{*}(r), G_{i}, Q_{i}, Q_{j}\right)=\delta r,
\end{aligned}
$$

$f_{v_{i j}}\left(l_{i}^{*}(r), v_{i i}^{*}(r), v_{i j}^{*}(r), y_{i i}^{*}(r), y_{i j}^{*}(r), G_{i}, Q_{i}, Q_{j}\right)=3 \delta,(2 \mathrm{c})$

$f_{y_{i i}}\left(l_{i}^{*}(r), v_{i i}^{*}(r), v_{i j}^{*}(r), y_{i i}^{*}(r), y_{i j}^{*}(r), G_{i}, Q_{i}, Q_{j}\right)=p_{y_{i}},(2 \mathrm{~d})$

$f_{y_{i j}}\left(l_{i}^{*}(r), v_{i i}^{*}(r), v_{i j}^{*}(r), y_{i i}^{*}(r), y_{i j}^{*}(r), G_{i}, Q_{i}, Q_{j}\right)=p_{y_{j}} \cdot(2 \mathrm{e})$

Equation (2a) informs us that the individual chooses the amount of land to be utilized for his/her residence at the quantity level at which the marginal benefit produced by land holding - the left hand side of equation $(2 \mathrm{a})$ - is equal to its marginal cost. The marginal cost is equal to the sum of the market price paid for each tract of land and the tax paid for each tract of land. Condition (2b) states that the individual determines the level of visitation to the city center by equating the marginal benefit from visitation - left hand side of equation (2c) - to the marginal cost of doing so. The marginal cost is equal to the transportation cost associated with each visit. Condition (2c) is similar in spirit. It says that the individual level of touristic visitation is determined according to the rule that the marginal benefit from touristic visitation is equal to the marginal cost of touristic visitation. Equations (2d) and (2e) show that the levels of local private goods and services consumption and touristic consumption are determined according to the same rule; namely, marginal benefit from each type of consumption is to the marginal cost (i.e., price) of each type of consumption.

The system of equations $(2 \mathrm{a})-(2 \mathrm{e})$ yields the demand functions for an individual of type $r$ in city $i$. These functions inform us how the individual responds to changes in prices and levels of composite local public good and public landscaping. In principle, one can invoke the Implicit Theorem Function in order to implicitly define the endogenous variables, $\left\{l_{i}^{*}(r), v_{i i}^{*}(r), v_{i j}^{*}(r), y_{i i}^{*}(r), y_{i j}^{*}(r)\right\}$, as functions of the exogenous variables, $\left\{p_{l i}(r), p_{y i}, p_{y j}, \delta, r, G_{i}, Q_{i}, Q_{j}\right\}$ - these implicit functions are the demand functions:

$l_{i}^{*}(r)=l_{i}^{*}\left(p_{l i}(r), p_{y i}, p_{y j}, \delta, r, G_{i}, Q_{i}, Q_{j}\right),(3 \mathrm{a})$

$v_{i i}^{*}(r)=v_{i i}^{*}\left(p_{l i}(r), p_{y i}, p_{y j}, \delta, r, G_{i}, Q_{i}, Q_{j}\right)$,

$v_{i j}^{*}(r)=v_{i j}^{*}\left(p_{l i}(r), p_{y i}, p_{y j}, \delta, r, G_{i}, Q_{i}, Q_{j}\right)$,

$y_{i i}^{*}(r)=y_{i i}^{*}\left(p_{l i}(r), p_{y i}, p_{y j}, \delta, r, G_{i}, Q_{i}, Q_{j}\right)$,

$y_{i j}^{*}(r)=y_{i j}^{*}\left(p_{l i}(r), p_{y i}, p_{y j}, \delta, r, G_{i}, Q_{i}, Q_{J}^{\mathrm{e}}\right)$

Our earlier assumptions for the sub-utility function $f($.) enable us to obtain some qualitative insights about the behavioral responses embodied in the demand functions. For example, we can say that the individual demand for land does not depend on the price of touristic goods and services and on the level of public landscaping at the touristic city because the marginal benefit of holding land does not change in response to changes in the level of consumption of touristic goods and services orin the level of touristic public landscaping. However, the demand for land should change in response to changes in either the levelof visits to the city center or in the level of composite local public goodprovided at one's city of residence. The marginal benefit of holding land rises as these variables rise, yielding positive responses on the quantity of land demanded. Furthermore, since each individual's visit to the city center becomes more attractive if either the level 
of consumption of local private goods and services or the level of public landscaping rises, each individual should be expected to visit the city center more frequently if either the level of consumption of local private goods and services or the level of public landscaping rises. These effects, in turn, imply that the demand for land also changes if either of these variables changes - the channel is indirect: first, there is the effect on visits to the city center. Then there is the effect of a change in visits on the quantity of land demanded. Thus, land demand should be positively (negatively) affected by the variables that positively (negatively) affect visits to the city center. As visits to the city center is positively affected by an increase in the level of public landscaping, we should also expect that the demand for land should rise in response to an increase in the level of public landscaping!

Other interesting behavioral hypotheses can be made using similar reasoning. However, to simplify exposition and provide readily visible behavioral hypotheses, let us assume that the sub-utility function takes the following functional form: $f()=.l_{i}(r)\left[B_{L}+G_{i}+v_{i i}(r)-l_{i}(r)\right]+y_{i i}(r)\left[v_{i i}(r)-y_{i i}(r)\right]+y_{i j}(r)\left[v_{i j}(r)-y_{i j}(r)\right]$ $+G_{i}\left(B_{G}-G_{i}\right)+Q_{i}\left[v_{i i}(r)-Q_{i}\right]+Q_{j}\left[v_{i j}(r)-Q_{j}\right]-v_{i i}^{2}(r)-v_{i j}^{2}(r)$, (4)

where $B_{L}>0$ can be understood as the value of the housing structure, which is fixed and identical for all individuals. According to this formulation, the marginal benefit of holding land, $B_{L}+G_{i}+v_{i i}(r)-2 l_{i}(r)$, rises with the level of composite local public good provided in city $r, G_{i}$, and with the number of visits made to the city center, $v_{i i}(r)$. Note that $f_{l_{i} G_{i}}(r)=f_{l_{i} v_{i i}}(r)=1$. In addition, the marginal benefit of consuming local private goods and services, $v_{i i}(r)-2 y_{i i}(r)$, depends crucially on the number of visits made to the city center. In fact, if this individual does not make any visit to the city center, he/ she has no incentive to consume local private goods and services and derives no benefit from public landscaping i.e., his/her demand for public landscaping is always zero in such a case. This seems logical: if no one visits the city center, there cannot be any economically viable activity there because there will not be any demand at all! We also assume that $B_{G}>0$.

Given (4), we can rewrite equations $(2 \mathrm{a})-(2 \mathrm{e})$ as follows:

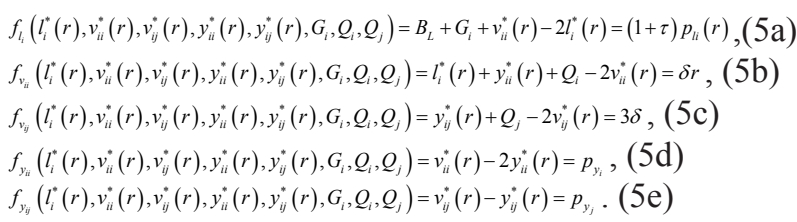

Solving the system $(5 a)-(5 e)$, we obtain the demand functions:

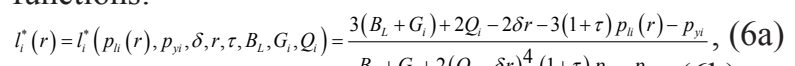

$$
\begin{aligned}
& v_{i i}^{*}(r)=v_{i i}^{*}\left(p_{i l}(r), p_{y i}, \delta, r, \tau, B_{L}, G_{i}, Q_{i}\right)=\frac{B_{L}+G_{i}+2\left(Q_{i}-\delta r\right)^{4}(1+\tau) p_{u}-p_{y i}}{2},(6 \mathrm{~b}) \\
& v_{i j}^{*}(r)=v_{i j}^{*}\left(p_{y j}, \delta, Q_{j}\right)=\frac{2\left(Q_{j}-3 \delta\right)-3 p_{y j}}{3},(6 \mathrm{c}) \\
& y_{i i}^{*}(r)=y_{i i}^{*}\left(p_{i t}(r), p_{y i}, \delta, r, \tau, B_{L}, G_{i}, Q_{i}\right)=\frac{B_{L}+G_{i}+2\left(Q_{i}-\delta r\right)-(1+\tau) p_{i t}(r)-3 p_{y i}}{4},(6 \mathrm{~d}) \\
& y_{i j}^{*}(r)=y_{i j}^{*}\left(p_{i j}, \delta, Q_{j}\right)=\frac{Q_{j}-3 \delta-2 p_{y j}}{3} .(6 \mathrm{e})
\end{aligned}
$$

In sum, we can make the following behavioral hypotheses:

(i) the individual demands for land, visits to the city center and local private goods and services in city $i$ rise with the value of the housing structure, with the level of the composite local public good provided in this city and with this city's level of public landscaping; however, they decrease with the transportation cost, with the distance of the residential location from city center, with the land tax rate, with the land price and with the price of the local private goods and services;

(ii) the individual demand for land in city $i$ is more sensitive to changes in either the value of the housing structure or the city's level of composite local public good than to changes in the city's level of landscaping;

(iii) the individual demands for visits to the city center and local private goods and services in city $i$ are more sensitive to changes in the city's level of public landscaping than to changes in either the value of the housing structure or the city's level of composite local public good;

(iv) the individual demands for touristic visits and touristic private goods and services rise with the level of public landscaping available in the touristic city, but falls with transportation cost and the price of touristic goods and services.

The analysis above makes it clear that the quality of public services may play a key role in motivating residents to visit the city center, purchasing local land and private goods and services, and also in stimulating tourism. The analysis, however, has a limited reach since it does not consider the mechanisms that determine market prices and whether the market prices themselves depend on the quality of public services. This is to say, the results of the analysis so far may underestimate or overestimate the overall impacts that public landscaping and the composite local public good have on the local industry, local land markets and local welfare.

We will now turn our attention to the mechanisms that determine prices of land and of private goods and services in both cities. We start by assuming that in each city there is a single land supplier - the local government - and that each local government does not exert market power on the sale of land lots. The local governments supply land of varying quality. The quality of a particular land lot in each city is proportional to the distance between its location and the city center. For land of quality $r \in[0,1]$ in city $i$ there are $2 \pi r$ lots of similar size (i.e., on the same circumference) and thus there are $2 \pi r$ buyers (assuming a buyer can purchase at most one lot). For such land quality, the market clears (i.e., demand is equal to supply) if and only if

$2 \pi r l_{i}^{*}\left(p_{l i}(r), p_{y i}, \delta, r, G_{i}, Q_{i}\right)=2 \pi r \Leftrightarrow l_{i}^{*}\left(p_{l i}(r), p_{y i}, \delta, r, G_{i}, Q_{i}\right)=1$. (7)

The left hand side of the first equation in (7) gives us the total number of land buyers - the length of the circumference of radius $r$ is equal to $2 \pi r$. Remember that the individual land demand function for an individual of type $r$ is given by equation (6a). Thus, equations (6a) and (7) imply

$p_{l i}^{*}\left(p_{y i}, \delta, r, \tau, B_{L}, G_{i}, Q_{i}\right)=\frac{3\left(B_{L}+G_{i}\right)+2 Q_{i}-2(2+\delta r)-p_{y i}}{3(1+\tau)}$.

Equation (8) provides us with the price of a land lot of quality $r$ in city $i$. Hence, we can clearly state that the market price of a land lot of quality $r$ in city $i$

(i) increases with the value of the housing structure, and with the city's level of composite local public good and level of public landscaping; however, it is more sensitive to changes on the value of the housing structure and the city's 
level of composite local public good than to changes on the level of public landscaping;

(ii) decreases with transportation cost, land quality level and the price of local private goods and services; however, it is more sensitive to changes on transportation cost and land quality level than to changes in the price of local private goods;

(iii) decreases with the land tax rate.

We can now check how our earlier results regarding the various demand relationships are influenced by the price of land. By substituting equation (8) into equations (6b) and (6d), we obtain the demand relationships for visits to the city center and local private goods and services net of the land price faced by the individual. The results are as follows:

$v_{i i}^{*}\left(p_{y i}, \delta, r, Q_{i}\right)=\frac{2\left(Q_{i}+1-\delta r\right)-p_{y i}}{3}$,
$y_{i i}^{*}\left(p_{y i}, \delta, r, Q_{i}\right)=\frac{\left(Q_{i}+1-\delta r\right)-2 p_{y i}}{3}$.

Equations (9a) and (9b) clearly demonstrate that, net of the land price, the individual demands for visits to the city center and local private goods and services

(i) rise with the level of public landscaping and decrease with the transportation cost, with the distance between one's residence and the city center and with the price of local private goods and services;

(ii) do not depend on the value of the housing structure, the level of composite local public good and the land tax rate.

In addition, the individual demand for local private goods and services, net of the land price, is less sensitive to changes in public landscaping than the original individual demand for local private goods and services. This implies that, if one neglects land price effects, the effects promoted by changes in public landscaping on the demand for local private goods and services are overestimated relative to the situation in which one fully accounts for the land price effects.

Consider now the mechanisms that determine the prices of local private goods and services. We assume that local industries are oligopolistic; namely, the suppliers of local private goods and services are endowed with some market power. In addition, we assume that these suppliers compete on quantity choices rather than on price choices. The two local markets are separate in that suppliers of one locality do not compete with suppliers of another locality. However, suppliers of any locality sell goods and services to residents and tourists. They do not price discriminate - that is, they sell goods and services at the same prices to both residents and tourists.

To examine the problem faced by each local supplier, we first need to derive the aggregate demand for local private goods and services sold by city $i$.Using equation (9b) and the fact that there are $2 \pi r$ individuals of type $r$, the demand for local private goods and services by individuals of type $r$ who reside in city $i$ is equal to $2 \pi r y_{i i}^{*}\left(p_{y i}, \delta, r, Q_{i}\right)=2 \pi r\left(Q_{i}+1-\delta r-2 p_{y i}\right) / 3$. Hence, the demand for local private goods and services by all residents of city $i$ is equal to

$Y_{i i}^{*}\left(p_{y i}, \delta, \pi, r, Q_{i}\right)=\frac{2 \pi}{3} \int_{0}^{1} r\left(Q_{i}+1-\delta r-2 p_{y i}\right) d r=\frac{\pi\left[3\left(Q_{i}+1-2 p_{y i}\right)-2 \delta\right]}{9}$.
Using equation (6e) and the fact that there are $\pi$ individuals residing in each city, the demand for touristic goods and services in city $i$ is equal to

$Y_{j i}^{*}\left(p_{y i}, \delta, \pi, r, Q_{i}\right)=\pi y_{j i}^{*}\left(p_{y i}, \delta, r, Q_{i}\right)=\frac{\pi\left(Q_{i}-3 \delta-2 p_{y i}\right)}{3}$. (10b)

Adding equations (10a) and (10b) up yields the total demand for local private goods and services in city $i$ :

$Y_{j i}^{*}\left(p_{y i}, \delta, \pi, r, Q_{i}\right)=\pi y_{j i}^{*}\left(p_{y i}, \delta, r, Q_{i}\right)=\frac{\pi\left(Q_{i}-3 \delta-2 p_{y i}\right)}{3} \cdot(10 \mathrm{c})$

Let $\hat{Y}_{i}$ denote the total supply of local private goods and services in city $i$. The market for local private goods and services in city $i$ clears if the aggregate demand for local private goods and services equals the aggregate supply of such goods and services:

$Y_{i}^{*}\left(p_{y i}, \delta, \pi, r, Q_{i}\right)=\hat{Y}_{i} \Leftrightarrow p_{y i}\left(\hat{Y}_{i}, \delta, \pi, Q_{i}\right)=\frac{\pi\left(6 Q_{i}+3-11 \delta\right)-9 \hat{Y}_{i}}{12 \pi}$,

where $p_{y i}\left(\hat{Y}_{i}, \delta, \pi, Q_{i}\right)$ is the inverse aggregate demand for local private goods and services.

Suppose that there are $N_{i} \geq 2$ suppliers of local private goods and services in city $i$. The larger the number of suppliers is the more competitive it is the market for local private goods and services in city $i$. Supplier $n$, $n=1, \ldots, N_{i}$, in city $i$ chooses $\hat{y}_{n i} \geq 0$ to maximize profits $s_{\hat{y}_{n i}}=p_{y i}\left(\hat{Y}_{i}, \delta, \pi, Q_{i}\right) \hat{y}_{n i}-c\left(\hat{y}_{n i}\right)$, where $p_{y i}\left(\hat{Y}_{i}, \delta, \pi, Q_{i}\right) \hat{y}_{n i}$ is the total revenue earned by the supplier and $c\left(\hat{y}_{n i}\right)$ is the cost of producing $\hat{y}_{n i}$ units of output. We assume that the cost is increasing and strictly convex. To simplify exposition, we assume that the cost function is as follows: $c\left(\hat{y}_{n i}\right)=\hat{y}_{n i}^{2}$.

Since $\hat{Y}_{i}=\hat{y}_{1 i}+\hat{y}_{2 i}+\ldots+\hat{y}_{N_{i} i}$, we can write $\hat{Y}_{i}=\hat{y}_{n i}+\sum_{m \neq n} \hat{y}_{m i}$, for any $n$. Hence, we have

$s_{\hat{y}_{m}}=\left[\frac{\pi\left(6 Q_{i}+3-11 \delta\right)-9\left(\hat{y}_{n i}+\sum_{m \pm n} \hat{y}_{m i}\right)}{12 \pi}\right] \hat{y}_{n i}-\hat{y}_{n i}^{2}=\left[\frac{\pi\left(6 Q_{i}+3-11 \delta\right)-9\left(\hat{y}_{n i}+\sum_{m \pm n} \hat{y}_{m i}\right)}{12 \pi}-\hat{y}_{n i}\right] \hat{y}_{n i}$

The optimal quantity produced by the representative supplier in city $i$ is the quantity that solves the following equation:

$\left[\frac{\pi\left(6 Q_{i}+3-11 \delta\right)-9\left(\hat{y}_{n i}^{*}+\sum_{m \neq n} \hat{y}_{m i}^{*}\right)}{12 \pi}\right]-\frac{9 \hat{y}_{n i}^{*}}{12 \pi}=2 \hat{y}_{n i}^{*}$

The left hand side of equation (13) represents the marginal revenue of selling $\hat{y}_{n i}^{*}$ units of local private goods and services in the market. The right hand side of equation (13) gives us the marginal cost of producing $\hat{y}_{n i}^{*}$ units. Hence, the optimal quantity is the one that equates marginal revenue to marginal cost of production. It is straightforward to show that each supplier produces an equal quantity of output. We can write $\hat{Y}_{i}^{*}=N_{i} \hat{y}_{n i}^{*}$. Substituting this result into equation (13) and solving the implied expression yields

$$
\hat{Y}_{i}^{*}\left(\delta, \pi, N_{i}, Q_{i}\right)=\frac{N_{i} \pi\left(6 Q_{i}+3-11 \delta\right)}{3\left[3\left(N_{i}+1\right)+8 \pi\right]} .
$$

Given (14a), we obtain

$$
\hat{y}_{n i}^{*}\left(\delta, \pi, N_{i}, Q_{i}\right)=\frac{\pi\left(6 Q_{i}+3-11 \delta\right)}{3\left[3\left(N_{i}+1\right)+8 \pi\right]} \quad \text { and }
$$




$$
p_{y i}^{*}\left(\delta, \pi, N_{i}, Q_{i}\right)=\frac{(3+8 \pi)\left(6 Q_{i}+3-11 \delta\right)}{12\left[3\left(N_{i}+1\right)+8 \pi\right]} .(14 \mathrm{~b})
$$

It is also straightforward to show that each supplier makes a positive profit in equilibrium:

$$
s_{\hat{y}_{i i}}^{*}\left(\delta, \pi, N_{i}, Q_{i}\right)=\frac{\pi(3+4 \pi)\left(6 Q_{i}+3-11 \delta\right)^{2}}{36\left[3\left(N_{i}+1\right)+8 \pi\right]^{2}} .(14 \mathrm{c})
$$

Results (14b) inform us that the both the price of the local private goods and services and the optimal quantity supplied by each producer

(i) increase with the size of the market (i.e., the number of customers) and the level of public landscaping available in city $i$;

(ii) decrease with the transportation cost and the number of suppliers (i.e., the degree of competition).

It is also easy to show that the total supply of local private goods and services in city $i$ (as can be seen in (14a))

(i) increases with the size of the market, the city's level of public landscaping and the city's number of suppliers;

(ii) decreases with the transportation cost.

Finally, close inspection of each supplier's profits in equilibrium reveals that

(i) profits increase as the size of the market expands and as the level of public landscaping in city $i$ rises;

(ii) profits decrease as the market becomes more competitive and as the transportation cost rises.

Having determined the prices of local private goods and services, we can now compute all equilibrium quantities. They are as follows:

$$
\begin{gathered}
v_{i i}^{*}\left(\delta, \pi, r, N_{i}, Q_{i}\right)=\frac{72 N_{i}\left(Q_{i}+1-\delta r\right)+(3+8 \pi)\left[21+18 Q_{i}+\delta(11-24 r)\right]}{36\left[3\left(N_{i}+1\right)+8 \pi\right]}, \\
V_{i i}^{*}\left(\delta, \pi, N_{i}, Q_{i}\right)=\frac{\pi\left\{24 N_{i}\left[3\left(Q_{i}+1\right)-2 \delta\right]+(3+8 \pi)\left[3\left(6 Q_{i}+7\right)-5 \delta\right]\right\}}{36\left[3\left(N_{i}+1\right)+8 \pi\right]}, \\
v_{j i}^{*}\left(\delta, \pi, N_{i}, Q_{i}\right)=\frac{72 N_{i}\left(Q_{i}-3 \delta\right)+(3+8 \pi)\left[18 Q_{i}-3-61 \delta\right]}{36\left[3\left(N_{i}+1\right)+8 \pi\right]},(15 \mathrm{c}) \\
V_{j i}^{*}\left(\delta, \pi, N_{i}, Q_{i}\right)=\frac{\pi\left\{72 N_{i}\left(Q_{i}-3 \delta\right)+(3+8 \pi)\left[18 Q_{i}-3-61 \delta\right]\right\}}{36\left[3\left(N_{i}+1\right)+8 \pi\right]},(15 \mathrm{~d}) \\
v_{i j}^{*}\left(\delta, \pi, N_{j}, Q_{j}\right)=\frac{72 N_{j}\left(Q_{j}-3 \delta\right)+(3+8 \pi)\left[18 Q_{j}-3-61 \delta\right]}{36\left[3\left(N_{j}+1\right)+8 \pi\right]},(15 \mathrm{e}) \\
V_{i j}^{*}\left(\delta, \pi, N_{j}, Q_{j}\right)=\frac{\pi\left\{72 N_{j}\left(Q_{j}-3 \delta\right)+(3+8 \pi)\left[18 Q_{j}-3-61 \delta\right]\right\}}{36\left[3\left(N_{j}+1\right)+8 \pi\right]},(15 \mathrm{f}) \\
y_{i i}^{*}\left(\delta, \pi, r, N_{i}, Q_{i}\right)=\frac{18 N_{i}\left(Q_{i}+1-\delta r\right)+(3+8 \pi)[3+\delta(11-6 r)]}{36\left[3\left(N_{i}+1\right)+8 \pi\right]},(15 \mathrm{~g}) \\
y_{i j}^{*}\left(\delta, \pi, N_{j}, Q_{j}\right)=\frac{18 N_{j}\left(Q_{j}-3 \delta\right)-(3+8 \pi)(3+7 \delta)}{18\left[3\left(N_{j}+1\right)+8 \pi\right]},(15 \mathrm{k}) \\
Y_{i i}^{*}\left(\delta, \pi, N_{i}, Q_{i}\right)=\frac{\pi\left\{18 N_{i}\left[3\left(Q_{i}+1\right)-2 \delta\right]+(3+8 \pi)\left[3\left(4 Q_{i}+5\right)-\delta\right]\right\}}{54\left[3\left(N_{i}+1\right)+8 \pi\right]},(15 \mathrm{~h}) \\
y_{j i}^{*}\left(\delta, \pi, N_{i}, Q_{i}\right)=\frac{18 N_{i}\left(Q_{i}-3 \delta\right)-(3+8 \pi)(3+7 \delta)}{18\left[3\left(N_{i}+1\right)+8 \pi\right]},(15 \mathrm{i}) \\
18\left[3\left(N_{i}+1\right)+8 \pi\right]
\end{gathered}
$$

$$
\begin{aligned}
& Y_{i j}^{*}\left(\delta, \pi, N_{j}, Q_{j}\right)=\frac{\pi\left\{18 N_{j}\left(Q_{j}-3 \delta\right)-(3+8 \pi)(3+7 \delta)\right\}}{18\left[3\left(N_{j}+1\right)+8 \pi\right]}, \\
& p_{l i}^{*}\left(\delta, \pi, \tau, r, B_{L}, G_{i}, N_{i}, Q_{i}\right)=\frac{36 N_{i}\left[3\left(B_{L}+G_{i}\right)+2\left(Q_{i}-2-\delta r\right)\right]}{36(1+\tau)\left[3\left(N_{i}+1\right)+8 \pi\right]} \\
& +\frac{(3+8 \pi)\left[36\left(B_{L}+G_{i}\right)+18 Q_{i}+11 \delta-51-24 \delta r\right]}{36(1+\tau)\left[3\left(N_{i}+1\right)+8 \pi\right]}, \\
& t_{i}^{*}\left(\delta, \pi, \tau, r, B_{L}, G_{i}, N_{i}, Q_{i}\right)=\frac{\tau p_{l i}^{*}\left(\delta, \pi, \tau, r, B_{L}, G_{i}, N_{i}, Q_{i}\right)}{(1+\tau)},(15 \mathrm{n}) \\
& T_{i}^{*}\left(\delta, \pi, \tau, B_{L}, G_{i}, N_{i}, Q_{i}\right)=\frac{\pi \tau\left\{36\left(B_{L}+G_{i}\right)\left(N_{i}+3+8 \pi\right)+6 Q_{i}\left[4 N_{i}+3(3+8 \pi)\right]\right\}}{36(1+\tau)\left[3\left(N_{i}+1\right)+8 \pi\right]}, \\
& -\frac{48 N_{i}(1+\delta)+(3+8 \pi)(51+5 \delta)}{36(1+\tau)\left[3\left(N_{i}+1\right)+8 \pi\right]} .
\end{aligned}
$$

The equilibrium individual demands for visits to the city center, touristic visits made to city $i$ 's center, touristic visits made to city $j$, local private goods and services by city residents, touristic private goods and services by residents of city $j$ and touristic private goods and services by residents of city $i$, are given by equations (15a), (15c), (15e), (15g), (15i) and (15k), respectively. Close inspection of these expressions reveals that all the above quantities demanded

(i) increase with the level of public landscaping at either one's city center or one's touristic city center, with the size of the market, and with the degree of competitiveness of the local industry;

(ii) decrease with the transportation cost.

Equations (15b), (15d), (15f), (15h), (15j) and (15l) give us the aggregate demand counterparts of the individual demands shown in equations (15a), (15c), (15e), (15g), (15i) and $(15 \mathrm{k})$, respectively. They display the same types of behavioral responses as their individual demand counterparts. Equation (15m) tells us how the price of a land lot of quality $r$ in city $i$ responds to changes in the exogenous variables. The equilibrium price of a land lot of quality $r$ in city $i$

(i) increases with the value of the housing structure, with the city's levels of composite local public good and public landscaping, with the level of competitiveness in the city's local industry and with the city's market size;

(ii) is more sensitive to changes in either the value of the housing structure or the city's composite local public good than to changes in the city's public landscaping level. Equation (15n) informs us how the equilibrium land tax paid by a landowner of type $r$ in city $i$ responds to changes in the exogenous variables, which in addition to those that affect this landowner's land price also include the land tax rate. The effects are qualitatively identical to those observed for the equilibrium land price. Finally, equation (15o) provides us with the total tax revenue collected in city $i$ as a function of the exogenous variables. We can clearly see that the total tax revenue collected in city $i$

(i) increases with the value of the housing structure, with the city's levels of composite local public good and public landscaping, with the level of competitiveness in the city's local industry and with the city's market size;

(ii) is more sensitive to changes in either the value of the housing structure or the city's composite local public good than to changes in the city's public landscaping level. 


\section{CONCLUSION}

As the general equilibrium analysis of this paper clearly reveals, a city's public landscaping level is one of its most valuable jewels. An expansion in the level of public landscaping produces desirable results to the local community, since it increases the city's wealth, the city's revenue from tax collection and each resident's welfare.

The analysis is limited because it does not consider public policy or the impacts of an expansion of a city's public landscaping level on the labor pool and on the size of the local industry. Clearly, the increase in each resident's welfare associated with an expansion in the city's level of public landscaping should motivate workers from other locations to seek jobs in city beautiful. This should prevent increases in wage and production costs, and should also expand the size of the market. Another straightforward prediction is that the high profits made by local firms should attract firms from other locations, expanding the number of local suppliers, decreasing the price of the local private goods and services and hence increase sales to both residents and tourists.

The provision of high quality public landscaping is a promising avenue for city development, since it constitutes one the key elements of city beautiful. But, as with other forms of beauty, the beauty of the end product requires effort, artistic talent and vision from its producer. City managers, as producers of city beautiful attributes, are in the end those who should receive the glory for success or the blame for failure in their cities' beautification and development.

\section{REFERENCES}

CARLINO, G. A. Beautiful city. Federal Reserve Bank of Philadelphia Business Review (Third Quarter), p. 10-17; 2009.

FAYE, B., E. L. FUR. Square, plaza, piazza, place: What do we know about these targets of urban regeneration programmes? Urban Studies 49, p. 3081-3099; 2012.

PIVETTA, K. F. L.; PAIVA, P. D. O.; NERI, F. C. S. Paisagismo em Grandes Espaços. In: PAIVA, P. D. O., Paisagismo Conceitos e Aplicações, Lavras: Editora UFLA, 2008. 178-211p. 